\title{
New improvements in increasing trends of caesarean section: to compare the effectiveness of two techniques Misgav Ladach with Joel Cohen incision versus Munro Kerr with pfannenstiel incision for caesarean section
}

\author{
Kanchan Sharma, Ankita Mani*
}

Department of Obstetrics and Gynecology, AIIMS, Patna, Bihar, India

Received: 07 May 2019

Accepted: 11 June 2019

\author{
*Correspondence: \\ Dr. Ankita Mani, \\ E-mail: maniankitaamit@gmail.com
}

Copyright: ( ) the author(s), publisher and licensee Medip Academy. This is an open-access article distributed under the terms of the Creative Commons Attribution Non-Commercial License, which permits unrestricted non-commercial use, distribution, and reproduction in any medium, provided the original work is properly cited.

\begin{abstract}
Background: Caesarean section (C-section) is the most common surgery among women worldwide, and the global rate of this surgical procedure has been continuously rising. Hence, it is significantly crucial to develop and apply highly effective and safe caesarean section techniques. In this study, we aimed at assessing the safety and effectiveness of the Joel-Cohen-based Misgav Ladach technique and comparing the results with the transverse Pfannenstiel incision (Munro Kerr) for C-section.

Methods: It was a prospective randomised controlled trial conducted on 100 women undergoing caesarean section at Patna Medical College and hospital in 2017. Patients were randomly allocated in 2 groups and intra operative and postoperative findings (blood loss, duration of surgery, post op fever, wound complication, APGAR scores etc. were calculated.

Results: The duration of surgery was significantly low in Misgav Ladach technique (19.9 minutes vs. 29.54 minutes $p$ value <0.001) Misgav technique was found economically better method as only 1 suture was used in 43 patients ( $p$ value $<0.001$ ). Post operative recovery (ambulation and bowel transit time) was found much early in Misgav Ladach vs. Munro Kerr ( $p$ value <0.001).Post operative use of analgesics was significantly less in Misgav technique ( $p$ value $<0.0001)$. However no significant difference was observed in incidence of postoperative fever, blood loss and mean APGAR scoring of neonates.

Conclusions: From this study it can be concluded that Misgav ladach method of caesarean section is associated with better short time post operative outcomes, especially resulting in reduction of pain and postoperative hospital stay.
\end{abstract}

Keywords: Caesarean section, Joel-Cohen, Misgav-Ladach, Modified Misgav-Ladach, Pfannenstiel

\section{INTRODUCTION}

In 1916, Edward Cragin said "Once a caesarean, always a caesarean". In the third millennium is this dictum still true? If we analyze the rate of caesarean sections over the past decades, we find a rising trend worldwide making Caesarean section the most performed intra-peritoneal surgical procedure. ${ }^{1}$ World Health Organization (WHO) earlier recommended around 5-15\% rate of caesarean section in any population. ${ }^{2}$ However, recently WHO suggested that there is no recommendation regarding a specific rate neither at country nor at hospital level. The tribal population accounts for $8.4 \%$ of the total population of India. The overall rates of caesarean section in 2015-2016 are approximately $17.2 \%$ which was only $8.5 \%$ in $2005-2006$. 
There is no universal surgical technique for caesarean section. The wide variation in surgical techniques in practice can be attributed to many factors namely the clinical situation and the preference of the surgeon. ${ }^{3}$ There is a continuing search for satisfactory techniques of caesarean sections that should be safe, fast, simple, cost effective, carrying less postoperative morbidity and mortality allowing shorter stay at hospital. Aim of this study is to compare the two most common surgical techniques, Pfannensteil Kerr and Modified MisgavLadach represented by modified Joel Cohen incision in terms of finding the simplest intervention to achieve the goal of short intra-operative time with least tissue damage. The study was also aimed to evaluate the postoperative complications, analgesia and drop in hematocrit and to evaluate the short term outcomes for the baby in both techniques such as skin incision to delivery and APGAR score.

\section{METHODS}

This was a prospective randomised controlled trial conducted during the period of October 2015 to October 2017 in the Department of Obstetrics and Gynecology at Patna Medical College and Hospital; Patna. The study recruited 100 patients undergoing emergent or elective caesarean sections.

\section{They were randomised into two groups}

Group A: 50 patients undergoing caesarean section by using Munro kerr technique of caesarean section using pfannenstiel incision.

Group B: 50 patients undergoing caesarean section by using Misgav ladach technique of caesarean section using Joel-Cohen incision.

These patients had regular antenatal checkups and routine blood investigations and satisfied the inclusion and exclusion criteria.

\section{Inclusion criteria}

- Women undergoing delivery by their first lower segment caesarean section in most of the cases and a few cases of previous caesarean section also

- Preeclampsia Gestational age 37 weeks or more

- Women aged 18 years or more, and

- Average built patients (no extra fat in lower abdomen).

\section{Exclusion criteria}

- Previous lower abdominal surgery including caesarean section with high morbidity in the post operative period,

- History of any complications in the antenatal period, parturition and puerperium in the past pregnancy
- History of any obstetrical complications associated with present pregnancy like severe degree Placenta previa and abruptio placenta, hypertension, preeclampsia and eclampsia, maternal anemia

- $\quad$ BMI > 40 (extremely obese).

Joel Cohen introduced a new method of opening abdomen transversely by digital separation and retraction by stretching rectus ${ }^{4}$ which was further modified by Stark. ${ }^{5}$ The difference between the two techniques is given in the Table 1.

Pfannensteil incision is transverse skin incision 2 to $3 \mathrm{~cm}$ above the symphysis pubis, $8-12 \mathrm{~cm}$ long that curves gently upwards (smiley incision). Joel Cohen skin incision is $3 \mathrm{~cm}$ below the line joining the anterior superior iliac spines or 3-4 cm above symphsis pubis and is about $15-17 \mathrm{~cm}$ long.

All patients in both the groups were subjected to the following protocol:

- Detail history

- Clinical examination

- Review of the reports of the tests done during routine antenatal checkups

- Examination of the baby.

\section{Postpartum care}

Intravenous hydration on the day of intervention. Catheter removal on the $2^{\text {nd }}$ postoperative day and Antibiotic prophylaxis and 15 unit's oxytocin and analgesics were given to both groups. Visual analogue scale was used for assessment of pain with range of score 0 (no pain) to 10 (worst pain). ${ }^{7} \mathrm{CBC}$ investigation was sent after 24 hour. Oral fluids are commenced with the return of the normal bowel movements (usually 24 hours after the operation) and a light diet is enabled 48 hours after the intervention. Wound evaluation on $4^{\text {th }}$ day for any discharge, dehiscence, hematoma. Stitches are removed on the $7^{\text {th }}$ postoperative day.

\section{Statistical analysis}

Pearson Chi square \& Fischer's Exact test were used to compare the categorical data between the two groups while Mann Whitney $U$ test was used to compare the continuous data. $\mathrm{P}$ value $<0.05$ is applied as statistically significant.

\section{RESULTS}

In both the techniques there was no significant difference between indications for caesarean section.

The Table 2 showing the various indications of caesarean section in both the groups. The Table 3 showing the demographic distribution of the study population. The Mean age of the patients in Misgav Ladach group - 21.95 
years. The Mean age of patients in munro kerr group is 22.42 years. Around 18 patients in Munrokerr Group were primigravida which was comparable to 21 patients in Misgav Ladach technique. The mean geatational age of the patients in Munrokerr group was 39.1 weeks while it was 38.8 weeks in Misgav Ladach group. The main outcome measures evaluated are listed in Table 4.

Table 1: Difference of surgical steps between two groups.

\begin{tabular}{|lll|}
\hline Steps & Group 1 & Group 2 \\
\hline Incision on skin & Pfannensteil & Joel Cohen \\
\hline Rectus sheath and muscles & Sharp cut with scissor & Digital separation and retraction \\
\hline Peritoneum & Cut with scissor & Digital separation \\
\hline Incision on uterus & Cut with scissor & Digital separation \\
\hline Closure of uterus & 2 layers & Single layer closure \\
\hline Skin suture & $7-8$ silk stitches & 3 silk stitches \\
\hline
\end{tabular}

Table 2: The indication for caesarean between the two group.

\begin{tabular}{|lllll|}
\hline Sn. & Indication & Munrokerr group $(\mathrm{n}=50)$ & Misgav Ladach group $(\mathrm{n}=50)$ & P value \\
\hline 1. & Prev CS & 18 & 15 & Ns \\
\hline 2. & CPD & 9 & 8 & Ns \\
\hline 3. & Fetal distress & 8 & 9 & Ns \\
\hline 4. & Breech & 9 & 10 & Ns \\
\hline 5. & Labour dystocia & 6 & 8 & Ns \\
\hline
\end{tabular}

Table3: Demographic distribution between the two groups.

\begin{tabular}{|lll|}
\hline Parameters & Group (Murokerr) years & Group2 (Misgav Ladach) years \\
\hline Mean age & 21.95 & 22.42 \\
\hline Primi & 18 & 21 \\
\hline Multi & 32 & 29 \\
\hline Mean gestation age & 39.1 weeks & 38.8 weeks \\
\hline
\end{tabular}

Table 4: Difference of intraoperative and postoperative findings between the two groups.

\begin{tabular}{|lllc|}
\hline Parameters & Group 1 (Murokerr) & Group 2 (Misgav Ladach) & P value \\
\hline Mean blood loss & $608 \pm 82.81$ & $586 \pm 74.16$ & 0.216 \\
\hline Mean drop in Hb & $0.9 \mathrm{~g} / \mathrm{dl}$ & $0.7 \mathrm{gm} / \mathrm{dl}$ & 0 \\
\hline Mean drop in HCT & 0.7 & 0.6 & 0 \\
\hline Mean duration of surgery & $29.54 \mathrm{~min}$ & $19.9 \mathrm{~min}$ & $<0.001$ \\
\hline Incision to delivery time & $32(5-10 \mathrm{~min})$ & $31(<5 \mathrm{~min})$ & 0.001 \\
\hline Single no. of suture used & 1 patient & 43 patient & $<0.001$ \\
\hline Mean APGAR score at 1minute & 8.1 & 8.5 & 0 \\
\hline Postoperative analgesic use & 14 & 3 & $<0.001$ \\
\hline Postoperative fever and wound discharge & 2 & 1 & 0.55 \\
\hline Post operative bowel transit and ambulation & 24 hours in 7 & 12 hours in 9 & $<0.001$ \\
\hline
\end{tabular}

The Table 4 showing the difference of intra-operative and postoperative findings between the two groups. Mean blood loss in Munro kerr was $608 \mathrm{ml} \pm 82.81 \mathrm{ml}$ while it was $586 \mathrm{ml}$ in Misgav Ladach technique ( $p$ value is $0.216)$, mean drop in $\mathrm{Hb}$ was $0.9 \mathrm{~g} / \mathrm{dl}$ in Munro kerr and $0.7 \mathrm{~g} / \mathrm{dl}$ in Misgav Ladach group, however this difference was statistically non significant.
However, Misgav Ladach technique was found superior to Munro Kerr in emergency cases where faster surgery is needed like in fetal distress as incision to delivery time is 5- 10 mins in Munro kerr group but less than 5 mins in Misgav Ladach group $(\mathrm{P}<0.001)$ also mean duration of surgery was $29.54 \mathrm{~min}$ in Munro kerr group but 19.9min in Misgav Ladach group $(\mathrm{P}<0.001)$. 
Post operative need of analgesic was very less in Misgav Ladach group (3 patients) as compared to Munro kerr group (14 patients) $(\mathrm{P}<0.0001)$. Post operative recovery (ambulation and bowel transit time) was found much earlier in Misgav Ladach (12 hours in 9 patients) vs. Munro Kerr ( 24 hours in 7 patients)(p value $<0.001$ ). The reduction in pain and the speedy recovery enables mother to look after the newborn earlier and helps develop maternal bonding. However no significant difference was observed in incidence of postoperative fever (2 vs. 1) p value 0.55 and APGAR scoring of neonates (8.1 vs. 8.5) in Munrokerr and Misgav techniques respectively.

In Misgav Ladach group as compared to Munro kerr group, fewer sutures are used, fewer instruments are needed and duration of operation is shorter. This gives the staff time for other tasks besides offering economic benefits.

\section{DISCUSSION}

In the study by Naki et al, which compared the Misgav Ladach method and Munro Kerr method, had no statistical difference in the indication for caesarean section. ${ }^{6}$ In our study there was no statistical difference between indications of CS. In the study by Naki et al, in a randomized controlled trial, which compared the Misgav ladach method and Munro kerr method and the study by Gedikbasi et al, the total operative time was lesser in misgav ladach group. Results were similar to current study. ${ }^{3,6}$

Misgav Ladach group being faster is associated with the benefits of the method in emergency section compared to elective caesarean section RCOG also recommends Misgav Ladach technique for emergency section. ${ }^{7}$ Moreover, less time spent in the operating room enables the obstetric team to spend more time in the labor ward, particularly in overcrowded and inadequately staffed labor wards. In the study by Ahmed Elnaggar, the modified Misgav Ladach method pfannenstiel kerr method in women with previous caesarean section: a randomized controlled trial. ${ }^{7}$ The study authenticated that Misgav Ladach group significantly reduced the total operative time and extraction compared to pfannenstiel kerr method $(\mathrm{p}<0.001)$. Moreover, the Misgav group significantly reduced the requirement of sutures compared to pfannentiel kerr $(\mathrm{p}<0.005)$.

In a study by Banerjee $\mathrm{P}$, the duration of surgery was significantly shorter for Misgav Ladach group (16 minutes) versus the Munro Kerr method (28 minutes). ${ }^{8}$

Moreira et al and Popiela et al in the year 2002 concluded that the post-operative pain and post-operative hospital stay was significantly shorter in Misgave Ladach group. ${ }^{9,10}$ In a study by Ferrari et al, there was more severe post-operative pain in Munro Kerr group cases as compared to Misgav Ladach group as extended trauma can induce an increased inflammatory response which causes more pain. ${ }^{11}$ Darj et al, in a randomized controlled trial comprising 50 elective cases, reported a short operative time and decreased need for analgesics. ${ }^{12}$

Further, Darj et al in, Moreira et al and most of the previous randomized trials showed that mobilization from the bed was earlier in Misgav Ladch group compared to Munro kerr group. ${ }^{9,12}$

\section{CONCLUSION}

The Misgav Ladach method of caesarean section is associated with better short time post-operative outcomes, especially resulting in reduction of pain and postoperative hospital stay. In the Misgav Ladach group as compared to Munro kerr group, fewer sutures are used, fewer instruments are needed and duration of operation is shorter. This gives the staff time for other tasks besides offering economic benefits. As incision to delivery time is reduced, this Misgav Ladach method can be used in the cases of fetal distress. The reduction in pain and the speed of recovery enables the mother to look after the newborn baby earlier and helps develop maternal bonding. Long term effects of misgav ladach technique remain to be evaluated.

\section{Funding: No funding sources}

Conflict of interest: None declared

Ethical approval: The study was approved by the Institutional Ethics Committee

\section{REFERENCES}

1. Xavier P, Ayres-De-Campos D, Reynolds A, Guimarães M, Costa-Santos C, Patrício B. The modified Misgav-Ladach versus the PfannenstielKerr technique for cesarean section: a randomized trial. Acta Obstet Gynecol Scand. 2005;84(9):878-82.

2. World Health Organization. Appropriate technology for birth. Lancet. 1985;2(8452):436-7.

3. Gedikbasi A, Akyol A, Ulker V, Yildirim D, Arslan $\mathrm{O}$, Karaman E, et al. Cesarean techniques in cases with one previous cesarean delivery: comparison of modified Misgav-Ladach and Pfannenstiel-Kerr. Arch Gynaecol Obstet. 2011;283(4):711-6.

4. Joel Cohen S. Abdominal and vaginal hysterectomy. New techniques based on time and motion studies $2^{\text {nd }}$ ed. Ed. W.H. Heinemann, London. William Heinemann Medical Books Ltd; 1972:8-11.

5. Stark M. Technique of Caesarean Section: the Misgav Ladach method. Women's Health Today, Eds Popkin DR, Peddle LJ. Montreal, the Parthenon Publishing Group. 1994;10:81-5.

6. Naki MM, Api O, Celik H, Kars B, Yaşar E, Unal O. Comparative study of Misgav-Ladach and Pfannenstiel-Kerr cesarean techniques: a randomized controlled trial. J Matern Fetal Neanatal Med. 2011;24(2):239-44.

7. Royal College of Obstetrician and Gynecologist (RCOG). Clinical Guideline April 2004 Caesarean 
Section, Clinical Guideline April 2004 National Collaborating Centre for Women's and Children's Health; Published by the RCOG Press at the Royal College of Obstetricians and Gynecologists, 27 Sussex Place, Regent's Park, London NW1 4RG57 (11); 2002:725.

8. Poonam, Banerjee B, Singh SN, Raina A. The Misgav Ladach method: A step forward in the operative technique of caesarean section. Kathmandu University Med J. 2006;4:198-202.

9. Moreira P, Moreau JC, Faye ME, Ka S, Kane Gueye SM, Faye EO et al. Comparison of two cesarean techniques: classic versus Misgav Ladach cesarean. J Gynecol Obstet Biol Reprod. 2002;31:572-6.

10. Popiela A, Pańszczyk M, Korzeniewski J, Baranowski W. Comparative clinical analysis of cesarean section technique by Misgav Ladach method and Pfennenstiel method. Ginekol Pol. 2000;71:255-7.
11. Ferrari AG, Frigerio LG, Candotti G, Buscaglia M, Petrone M, Taglioretti A, et al. Can Joel-Cohen incision and single layer reconstruction reduce cesarean section morbidity? Int J Gynecol Obstet. 2001;72(2):135-43.

12. Darj E, Nordstrom ML. The Misgav-Ladach method for cesarean section compared to the Pfannenstiel method. Acta Obstet Gynecol Scand. 1999;78:37-41.

Cite this article as: Sharma K, Mani A. New improvements in increasing trends of caesarean section: to compare the effectiveness of two techniques misgav ladach with Joel Cohen incision versus Munro Kerr with pfannenstiel incision for caesarean section. Int J Reprod Contracept Obstet Gynecol 2019;8:2799-803. 